Mean Places of Comparison Stars.

\begin{tabular}{|c|c|c|c|}
\hline * & $\alpha \quad$ I 899.0 & $\delta_{1} 899.0$ & Authority \\
\hline $\mathbf{I}$ & $4^{\mathrm{h}} 35^{\mathrm{m}} 43^{\mathrm{s}} \cdot 2 \mathrm{I}$ & $+14^{\circ} 37^{\prime} 39^{\prime \prime} 9$ & Yar. \\
\hline 2 & $\begin{array}{lll}4 & 28 & 35.20\end{array}$ & +144548.0 & $W_{1} 4.54 I$ \\
\hline 3 & $428 \times 3.62$ & +14577.0 & AG. Berlin A. I 22 I \\
\hline 4 & 42020.60 & +151741.2 & AG. Berlin A. I 174 \\
\hline 5 & $421 \quad 50.37$ & +152146.6 & AG. Berlin A. I I 84 \\
\hline
\end{tabular}

\begin{tabular}{|c|c|c|c|}
\hline * & $\alpha 1900.0$ & $\delta \times 900.0$ & Authority \\
\hline 6 & $4^{h} \times 2^{\mathrm{m}} 14^{\mathrm{s}} \cdot 25$ & $+18^{\circ} 0^{\prime} 42^{\prime \prime} .9$ & A G. Berlin A. I I 29 \\
\hline 7 & $4930.3^{6}$ & +182222.2 & AG. Berlin A. I I I 5 \\
\hline 8 & $\begin{array}{lll}4 & 9 & 54.68\end{array}$ & +184247.7 & AG. Berlin A. I I I \\
\hline 9 & 4933.21 & +18444.5 & AG. Berlin A. I I I 6 \\
\hline
\end{tabular}

The observations were made with the filar micrometer of the $\mathbf{2}$ inch refractor.

Poughkeepsie, N. Y., I 900 March.

\title{
Discovery and Photographic Observations of a New Asteroid 1899 FD.
}

This extremely faint asteroid was discovered by its trail on a plate which had been exposed for four hours, on the night of Dec. 6,1899 , for the purpose of photographing the region of T Tauri and Hind's variable nebula with the Crossly reflector. For various reasons, mainly the pressure of other work, the asteroid could not be observed regularly and its discovery was not announced. At the time of the third photographic observation, on Jan. I 9, I 900 , it was not certainly visible with the 36 inch refractor, and its magnitude was taken to be 17 .

The following positions were deduced from measurements of the plates by Mr. Coddington and Mr. Palmer.

Mt. Hamilton, I 900 March.

\begin{tabular}{|c|c|c|c|}
\hline $1899-00$ & Mt. Ha. M.T. & $\alpha$ app. & $\delta$ app. \\
\hline Dec. 9 & $9^{\mathrm{h}} 29^{\mathrm{m}} 36^{\mathrm{s}}$ & $4^{\mathrm{h}} 3^{\mathrm{m}} 5^{2^{\mathrm{s}} \cdot 5^{8}}$ & $+19^{\circ} 14^{\prime} 51.9$ \\
\hline 26 & 8 I I 22 & 41 I I.0 I & +19222.2 \\
\hline Jan. I 9 & $753 \quad 35$ & $354 \quad 49.32$ & +19 I5 30.7 \\
\hline
\end{tabular}

From these observations elements have been computed by Mr. Palmer; and independently by Mr. Phipps, of the Students' Observatory, Berkeley. The values of $M$ and $\infty$ are uncertain, on account of the small eccentricity.

Fames E. Keeler.

\section{Elements of Asteroid 1899 FD.}

From the photographic observations of Dec. 9, Dec. 26, and Jan. 19, given in the preceding article, I have computed the following elements.

Epoch 1900 Jan. 0.0 Berlin M. T.

$$
\begin{aligned}
& M=29^{\circ} 4^{2} \quad 7^{\prime \prime} 9 \\
& \omega=4^{6} 3931.5 \\
& \delta 8=924439.0 \\
& i=3 \mathrm{I} 3 \mathrm{I5} .8 \\
& \varphi=1^{\circ} \text { I } 3^{\prime} 23^{\prime \prime} 3 \\
& \mu=736.622 \\
& \log a=0.455174
\end{aligned}
$$

The magnitude on Jan. 19 is taken to be 17.0

Mt. Hamilton, 1900 March.

H. K. Palmer.

\section{Beobachtungen des Planeten 1900 FC} a uf der k. k. Sternwarte in Wien von Dr. F. Palisa.

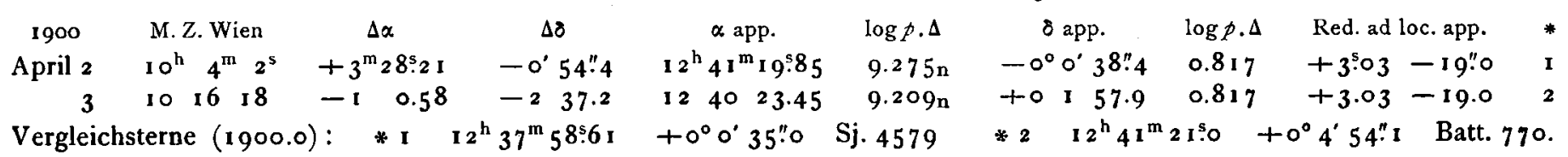

\section{Beobachtung des Planeten 1900 FC}

auf der Sternwarte des Collegio Romano in Rom von Prof. E. Millosevich.

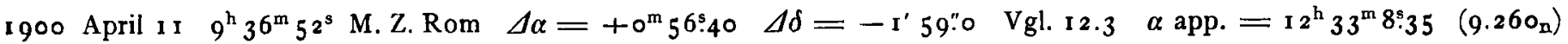
$\delta$ app. $=+0^{\circ} 19^{\prime} 2^{\prime \prime} .4(0.767)$ Red. ad l. app. $+3^{5.05}-\mathrm{rg} . \mathrm{r}$

Vergleichstern (1900.0): $\alpha=\mathrm{I}^{\mathrm{h}} 3^{2^{\mathrm{m}} 8^{\mathrm{s}}} 90 \quad \delta=+0^{\circ} 2 \mathrm{I}^{\prime} 4 \mathrm{I}_{5}^{\mathrm{l}} \mathrm{M}_{1} 8283(1 / 2), \mathrm{Sj} .4542$, Par. $1549 \mathrm{I}$. 